\title{
Productive Pedagogies: A Redefined Methodology for Analysing Quality Teacher Practice
}

\author{
Martin Mills, Merrilyn Goos, Amanda Keddie, Eileen Honan, \\ Donna Pendergast, Rob Gilbert, Kim Nichols, \\ Peter Renshaw and Tony Wright \\ The University of Queensland
}

\begin{abstract}
This paper identifies the ways in which the Productive Pedagogies framework has been refined as a research tool for evaluating classroom practice within a current study into issues of school reform in Queensland. Initially emerging from the landmark Queensland School Reform Longitudinal Study (1998-2001), the Productive Pedagogies has been taken up widely in Australia and internationally as both a research tool and metalanguage to support teachers to critically reflect on their practice. In this paper, following a brief description of the model's four dimensions, we detail how we have addressed some methodological concerns in using and modifying the framework for the present study. In response to critiques by other researchers and debates within our own research team, we justify our use of the framework. To these ends, we present a refined methodology that addresses the importance of pedagogical process, substantiates the inclusion of particular items within the framework, supports a critical approach to issues of difference, includes students' perspectives and recognises the significance of content knowledge in the assessment of quality pedagogy.
\end{abstract}

\section{Introduction}

This paper substantiates the methodology currently being utilised for a study of reform initiatives in Queensland schools commissioned by that state's Department of Education and Training (DET). This study is referred to as the Queensland Longitudinal Study of Teaching and Learning (QSTL). In its key focus on how issues of pedagogy, assessment and broader school organisation impact on student learning, the study is expected to revisit much of the work of the Queensland School Reform Longitudinal Study (QSRLS), conducted between 1998 and 2001 (Lingard et al., 2001). This landmark 
Australian study which involved the observation of approximately 1000 classrooms over a three year period examined the links between classroom practices and improved learning (Lingard, Hayes, Mills, \& Christie, 2003). The principal concerns raised in that study related to what were perceived to be generally low levels of quality pedagogy in Queensland classrooms. The current study is mindful of these concerns and along similar lines to the QSRLS supports a focus on productive pedagogies, particularly in terms of developing students' higher order intellectual skills and citizenship. The current study is also mindful of the key pedagogical recommendations the QSRLS identified as critical in improving productive performance and learning outcomes in schools. These included:

- A pressing need to enhance the intellectual demand of pedagogy in Queensland schools (specifically a general lack of higher order thinking, substantive conversation and critical analysis of knowledge);

- The need for more attention to be given to connecting student work to their biographies and the world outside the classroom;

- The need for more valuing of difference in pedagogies (Lingard et al., 2001, p. xxv)

It was during that study that the Productive Pedagogies and Productive Assessment frameworks emerged as research tools for exploring and evaluating classroom practices that have a positive impact upon the academic and social outcomes of all students, regardless of background. Premised on the belief that good teachers are central to positive outcomes for students, these frameworks were also subsequently presented as a useful metalanguage for teachers to critically reflect on, and enhance, their practice towards improving student learning (Lingard, Hayes, Mills \& Christie, 2003; Hayes, Mills, Christie, \& Lingard, 2006).

In line with this premise, senior DET officers have indicated that they are supporting a concerted attempt to cultivate a research culture in Queensland government schools that entails self-reflections and critical analysis of existing practices with a view to improving students' school experiences. They consider the QSRLS findings to be a significant impetus for justifying such a culture. Our current study is expected to reinforce in the Queensland educational community the importance of such research for informing education reforms in schools and classrooms. It also has an evaluative component in determining the impact of Education Queensland's investment in professional development around the Productive Pedagogies framework arising from the QSRLS. As with the QSRLS, the current study seeks to examine the quality of classroom practice in a diverse range of Queensland schools. To these ends, we are obtaining data on teacher practices, assessment tasks, student performances and teacher judgements with a view to providing important insights into better understanding the work of teachers. Also 
consistent with the QSRLS we have drawn on the Productive Pedagogies framework to structure our observations of classrooms. In this paper we outline how we have addressed some methodological issues in using and refining the framework in response to critiques by other researchers and debates within our own research team.

\section{Rationale for the Study}

The current study is the first phase of a longitudinal project intended to be undertaken over a six year period. The first phase, lasting 18 months, aims to survey approximately 2000 parents, 2000 students and 650 teachers from around 100 schools, as well as carrying out one week case studies of 18 schools, some of these were involved in the original QSRLS research. In the current study the focus is on middle years classrooms in Years 4, 6, 8 and 9 in English, mathematics, science and social sciences. In the case studies these classrooms are observed, assessment tasks and samples of student work are collected, and interviews are conducted with students, teachers, parents, and senior staff. Centrally held data on student performance on local, national and international standardised tests has also been accessed for analysis. The first phase of the project thus provides baseline data against which to measure change over the next six years.

In undertaking this study we acknowledge that many students are well served by schools; however, many do not benefit from the schooling process as much as could be the case (Teese \& Polesel, 2003; see also Mills \& Gale, 2007). We recognise the broad social conditions which work against the interests of students from particular communities (Comber \& Kamler, 2004) and understand the difficulties that many in schools face in terms of improving the educational outcomes of students from disadvantaged backgrounds (Comber, Badger, Barnett, Nixon, \& Pitt, 2001; Thomson, 2002). The social and economic conditions within which many students live make the task of providing equitable outcomes for all students extremely difficult, and schooling alone without serious attempts to alleviate poverty, racism, and other forms of injustice cannot address many of the inequities existing within classrooms. Nevertheless, we argue that education systems, schools and individual classrooms can change to better meet the educational needs of students of diverse socio-economic backgrounds, ethnicities, geographic locations and physical abilities. This is imperative in the light of international comparison studies that have highlighted the inequitable distribution of high quality outcomes delivered by Australian education systems (McGaw, 2006; Thomson, Creswell, \& De Bortoli, 2004; Dusseldorp Skills Forum, 2005). In Queensland, there are key equity issues to be discussed at the policy level (Singh \& Taylor, 2007). For example, a report on social disadvantage amongst Australian children states in regard to the Child Social Exclusion Index, based on such measures as access to computers, levels of parental income and parental occupations (or lack thereof), that 
"25 per cent of children living in Queensland [fall] into the most disadvantaged decile" (Harding, McNamara, Tanton, Daly, \& Yap, 2006, p. 27).

Although the focus of this study is the classroom, realising high quality outcomes for students will require more than teachers simply changing their practices. They also need the support of school communities and the systems within which they are situated. Research in Finland, often cited as an example of an education system that combines high quality with high equity, indicates that these supportive measures include respect of and trust in teachers' professionalism, advanced qualifications for entry into the profession, an avoidance of high stakes testing and accompanying appraisal of teachers based on notions of accountability, high levels of student support in the early years of schooling, and a focus on learning that takes into account more than just academic achievement (Sahlberg, 2007; see also Routti \& Ylä-Antilla, 2006; Simola, 2005). Thus identifying a framework for classroom observation reminds us of the need to avoid making judgments about individual teachers and imposing standards upon them. In developing this study we wanted teachers to know that our classroom observations are as much about learning from them as determining the quality of particular classroom practices. Any other approach is likely to alienate teachers and to be counter-productive to the longer term aims of a project such as this - to improve the educational outcomes of students.

\section{The Productive Pedagogies as an observation instrument}

Our selection of the Productive Pedagogies framework as a potential observation instrument for the current study was guided by the need for a valid form of measurement that could (i) capture classroom processes and events that occur with some frequency and regularity across the system, (ii) provide an index of the variation in the quality of teaching and learning occurring in different classrooms, and (iii) allow different dimensions of quality to be identified and clearly described so that system-wide improvements in teaching quality can be designed on the empirical evidence gathered. As indicated earlier, we recognise the central role of the teacher in improving student outcomes and so our focus is on the activities, strategies and behaviours of teachers in enabling certain kinds of student engagement and practices in the classroom. In doing so we also acknowledge that learning is not limited to the classroom and may take place across a school (Mills, 1996, 1997).

Studies of whole systems that do not rely solely on self-report questionnaires or single case studies and narrative descriptions are rare. Two examples are the authentic pedagogy research of Newmann and Associates (1996) and the Productive Pedagogies research conducted as part of the QSRLS (Lingard et al., 2001). The former research was significant in the development of the latter model in that a number of items from the 
authentic instruction observation instrument were included directly in the Productive Pedagogies framework. The Queensland researchers then added other items to take into account particular expectations of Australian classrooms and the Australian context, drawing on diverse literatures on learning theories, critical literacy, sociology of education, learner identities and curriculum theory. This approach has been described as a jigsaw methodology that brings together "pieces of the puzzle about influences on learner outcomes that are often spread over and embedded within a range of research studies" (Alton-Lee, 2004, p. 2). Factor analysis following the QSRLS observational data gathering - where a 5 point likert scale (explained in more detail below) was used to assess practice relating to 20 pedagogy items - led to the determination of the four dimensions of the Productive Pedagogies framework: intellectual quality, connectedness, supportive classroom environment, and valuing and working with difference ${ }^{1}$. Evidence of all four dimensions in classrooms is seen to reflect optimum conditions for enhancing student learning (Lingard et al., 2001).

The Productive Pedagogies framework has been written about extensively (e.g., Hayes, Johnston, \& King, 2006; Lingard, Hayes \& Mills, 2003; Lingard, Hayes, Mills, \& Christie, 2003) and used in other research projects (e.g., Lingard, Martino, Mills, \& Bahr, 2002; Allen, 2003; Martino \& Berrill, 2003; Louden et al., 2005; Pendergast et al., 2005; Keddie, 2006; Keddie \& Mills, 2007; Marsh, 2007; Munns, 2007). It has been adapted as educational policy in New South Wales (NSW Department of Education and Training, 2007) as well as in Queensland. These developments are indicative of widespread acceptance of the framework amongst sections of the research community in Australia and internationally, and locally amongst policy makers and teachers. Nevertheless, there have been some critiques of the original Productive Pedagogies framework (e.g., Sellar \& Cormack, 2006), including from some of its original developers (Ladwig, 2007). These and other considerations led us to modify and refine the framework for use in our current study. We proceed next to a justification of particular aspects of the original model and then to an explanation of the refinements we have made.

\section{Aspects of the model}

One of the primary reasons for working with the Productive Pedagogies framework for this study is that it promotes the provision of a high quality education for all students, and especially students from disadvantaged backgrounds (Lingard et al., 2001). For students to demonstrate high level intellectual outcomes they must be provided with a learning environment that stimulates intellectual activity. This type of learning is encouraged when the material covered connects with the students' various worlds, especially for students who have disengaged or are in danger of disengaging from school. There is also ample evidence to suggest that the supportiveness of a classroom is critical for the achievement of high level outcomes for students, especially for those who have traditionally been failed by the education system. In a time and 
world that is characterised by diversity, complexity, rapid change and conflict, achieving positive social outcomes and values requires that students learn to work with and value difference. We would also claim that valuing difference delivers academic benefits to those students who often feel disconnected from schooling due to a failure to have their own "differences" valued within the classroom. These arguments led us to retain the original four dimensions of the Productive Pedagogies framework intellectual quality, connectedness, supportive classroom environment, and valuing and working with difference - in our reworked version. Without elaborating in detail on the various items that constitute the model, we make some general points about the various dimensions of the framework.

Intellectual Quality The intellectual quality dimension of the Productive Pedagogies model stresses the importance of all students, regardless of background and perceived academic ability, being presented with intellectually challenging work (DarlingHammond, 1997; Newmann \& Associates, 1996; Sizer, 1996; Boaler, 2002; Sarra, 2006; Perry, Steele, \& Hilliard III, 2003). Challenging work is of particular importance for students from traditionally underachieving backgrounds, for example, Indigenous students and students from low socioeconomic backgrounds. There are many structural practices in schools, for example streaming, which work against all students experiencing intellectually challenging work (see for example, Boaler, 1997; Boaler, William, \& Brown, 2000; Ireson, Hallam, \& Plewis, 2001; Wiliam \& Bartholomew, 2004). The current "curriculum wars" over, for example, literacy (see Snyder, 2008) and history (Clark, 2008), that have been occurring in Australia and elsewhere represent another threat to intellectual quality. Contrary to some claims that have been made in the media that "postmodern curricula" and the like are "dumbing" schools down (see for instance Donnelly, 2004), we suggest that some of the back to basics calls are likely to do just this, and that it will be students in "disadvantaged" schools who are most likely to be "drilled and skilled" in ways that do not encourage high level thinking and critical engagement with knowledge.

Connectedness Concerns have been expressed that new forms of curricula and pedagogy that appear to focus on making classes relevant for students often reflect a dumbing down of lessons and also do not extend students' access to cultural capital by relying upon what they already know and on their own cultures. This is particularly likely to be the case when the curriculum is designed to accommodate the needs of low achieving students. However such an approach is problematic, for as DarlingHammond (1997) has argued: "Active learning aimed at genuine understanding begins with the disciplines, not with whimsical activities detached from core subject matter concepts as some critics of hands-on learning suggest, and it treats the disciplines as alive, not inert" (p. 107). As with the productive pedagogies work, she claims there has to be a focus on developing students' deep-understanding in worthwhile and 
meaningful contexts and that this will require students to use higher order thinking that goes beyond simple recall, recognition, and reproduction to analysis, synthesis, evaluation, and production of ideas and performances.

Supportive Classroom Environment Providing all students with intellectually challenging classrooms is critical for improving academic outcomes. However, adoption of this approach has at times taken a conservative turn in overlooking the importance of relationships. In arguing for the creation of a supportive classroom, the productive pedagogies framework suggested that students be given a voice in the classroom in order to have some say over the direction that activities take within various units of work, that explicit criteria be provided to students so that expectations are clear, and that a classroom environment is created where students are prepared to take risks with their learning. While care is central to good teachers' work (Lingard et al., 2001), Hargreaves (2003) has stated that, "Care must become more than charity or control: it must become a relationship in which those who are cared for (pupils or parents) have agency, dignity and a voice" (p. 47). In developing positive and mutually supportive relationships, the importance of breaking down the power imbalances between teachers and students is particularly important, given many students' resistances to being overpowered and controlled (Keddie \& Churchill, 2004; Martino \& PallottaChiarolli, 2003; Mills, 1996, 1997). Much has been made about the need for explicit criteria in the classroom and the ways in which those familiar with the mores and nuances of what makes a "good" student have an advantage over students who are not at ease with the schooling process (Bourdieu \& Passeron, 1977; Cope \& Kalantsiz, 1995). However, explicit expectations have to be both related to students' schoolwork and to their performances of being a good citizen - and here we broaden the notion of a good student to include one who is concerned not just about academic achievement but also with being a positive member of a democratic community. This is taken up in the next dimension.

Valuing and Working with Difference The working with and valuing difference dimension of Productive Pedagogies is the one aspect of the model that has been the source of much debate (Ladwig, 2007; Lingard, 2007). In the original QSRLS study very few of the items that make up this dimension were observed in classrooms to any great extent. The study noted that teachers were not uncommitted to valuing students' difference, but that at times they were afraid of getting it wrong - and this was especially the case in relation to Indigenous issues (Lingard et al., 2001). We acknowledge some of the problems with expressions such as "valuing diversity" (see also Cooper, 2004). For example, questions relating to whose diversities are worthy of support, and whose are not, have to be confronted. Classroom practices that work with the difference dimension facilitate students' exposure to understandings of the ways in which power works to construct particular forms of domination and subordination. Its presence in classrooms 
will also enable students to become aware of the ways in which various factors including gender, race/ethnicity, age and socioeconomic status affect their identities (Frankenstein, 1997, 2001; Gutstein, 2003). To a great extent the presence of this dimension in a classroom enables teachers to teach for democracy; that is to provide students with the skills and knowledges necessary for them to act as responsible members of a democratic community (Malloy, 2002; Skovmose \& Valero, 2002).

\section{Critiques and Limitations of the Productive Pedagogies Framework}

In selecting the Productive Pedagogies framework for this research project, we are mindful of Debra Hayes et al.'s (2006) comment about educational research involving classroom observations that "it is difficult to agree on what to look for and even more difficult to agree on what is seen" (p.1). This lack of agreement about what to observe in classrooms and the fraught consequences of including some things to be observed and some not is reflected in healthy debate amongst the academic community about aspects of the Productive Pedagogies framework. Critiques have focused on what is most important to look for (e.g., Luke, Freebody, Shun, \& Gopinathan, 2005; Luke \& Hogan, 2006; Sellar \& Cormack, 2006) as well as the validity of what is seen (e.g., Ladwig, 2007).

Sellar and Cormack (2006), for instance, whilst generally supportive of the Productive Pedagogies research suggest that it is too focused on the outcome or production of pedagogy, rather than describing its actual movement. They suggest, for example, in reference to the pedagogy deep knowledge that movement towards this pedagogy involves researching, designing, communicating, transforming, performing and reflecting (p. 5). They contend in relation to their framework that such "processes are . . complementary to others such as the productive pedagogies". Along these lines, they stress the importance of considering the modes of interrelation in the classroom that lead to outcomes such as deep knowledge (p. 6).

Research undertaken in Singapore, which involved members of the original QSRLS research team, while drawing on the dimensions of Productive Pedagogies, placed greater focus on the significance of knowledge in the classroom (Luke et al., 2005; see also Luke et al., 2006). The coding scheme used in this research is not readily available (see Shegar \& Rahim, 2005, for research that uses this scheme), but it is described as looking ". . . at how knowledge is framed; that is, how the social interaction of teacher/student discourse and behaviour creates a mediating environment for working with ideas, knowledge and texts, using a range of semiotic tools and artefacts". In so doing there is a focus on depth of knowledge, knowledge criticism and knowledge manipulation. The coding scheme for this research also dropped the notion of higher order thinking from the original Intellectual 
Quality dimension of the Productive Pedagogies because of the suggestion that it "proved too high an inference as an observational construct" (Luke et al., 2005, p. 19).

The difference dimension of the Productive Pedagogies framework has been critiqued both for its inclusion in the model and for not going far enough in terms of critically defining how differences might be valued. Researchers from the University of Western Sydney have been working on the concept of enabling pedagogies - developed in response to their "scholarly critique" of the Productive Pedagogies (NSW Department of Education and Training, 2007). They suggest that there is a need "to move beyond the limitations of 'valuing' diversity, as outlined in Productive Pedagogies, to a critical understanding of difference that is cognisant of the inadequacies of liberal tolerance discourses and that recognises micro and macro power relations, and problematises knowledge about 'community'".

Ladwig (2007), who was involved in the original QSRLS research team and was a key figure in the development of NSW's three dimensional Quality Teaching Model $^{2}$ that incorporates most of the elements of the Productive Pedagogies framework (NSW Department of Education and Training, 2007; Ladwig, 2005; see McConaghy, 2006 for a critique of this model), has argued that there is no empirical evidence to advocate for the inclusion of recognition of difference into a model of quality pedagogy and thus this dimension does not appear in the NSW model. He suggests that the lack of empirical evidence about this phenomenon in the observed classrooms may stem from one of two things: either very few teachers ever demonstrate particular elements of that dimension, or some of the items were poorly defined in the observation manual.

In addition to these published critiques we are aware from our experiences of some other limitations of the QSRLS research. These include lack of student voice in the research, inadequate focus on teachers' pedagogical content knowledge, and methodological issues relating to the depth of content knowledge of observers undertaking observations of lessons in disciplines with which they were not familiar. The next section outlines how we are addressing all of these issues.

\section{Refinement of the Productive Pedagogies Framework}

\section{Refining and extending the focus of classroom observations}

In relation to Sellar and Cormack's (2006) arguments about distinguishing between pedagogical outcomes and pedagogical processes, the case study reports that accompany our classroom observations will seek to identify the presence of such processes, without coding for them, in order to comment on their relationship to the more "outcome" focussed elements in the Productive Pedagogies framework. Likewise, 
as with many of the features of the Singapore classroom observations, we will be providing more detailed pictures of the classroom than was the case in the original QSRLS research. Broader understandings of how particular pedagogical processes might align with a particular productive pedagogy are being availed to these ends through a requirement that each observer identify and briefly describe the key teacher strategies used in each lesson observation and through space in each teacher's corresponding interview to comment and elaborate on the purpose and efficacy (or otherwise) of such strategies. We avoided going down the path of quantifying such strategies, for instance, through documenting the amounts of time that teachers might spend on a particular process, for example, communicating through procedural talk. Moreover, whilst we recognise the importance of the distinctions made between processes such as designing, communicating and reflecting (Sellar \& Cormack, 2006) and can see why in some studies there might be a specific focus on these, our view is that such processes are incorporated or embedded within a number of elements within the Productive Pedagogies model and that to code for them separately would hinder the broader analyses of classrooms that we are seeking to undertake.

In reference to the exclusion of the item higher order thinking from the Singapore version of the productive pedagogies model, we strongly defend the inclusion of this item for observation in our current study. Most notably as one of the original item in the authentic pedagogy (Newman \& Associates, 1996) framework, its significance in stretching students intellectually through the application and synthesis of knowledge, beyond the other intellectual quality items (e.g., deep knowledge, deep understanding) is well established. Moreover, the original QSRLS findings around the low levels of higher order thinking in classrooms and their association with low levels of intellectual demand within pedagogy more broadly, clearly support its inclusion in the model. However, we do acknowledge the high inferences observers must apply when assessing the extent to which this item is or is not absent in classrooms. For these reasons significant training and discussion occurred amongst the around, for example, how higher order thinking in mathematics might be different from, but similar to higher order thinking in English. The diverse expertise of the research team across mathematics, English, science and the social sciences facilitated this, as it did in terms of conducting observations of particular curriculum areas. Early analysis of inter-rater reliability scores indicate a high level of agreement amongst the researchers in this project.

\section{Refining the Difference dimension}

In relation to Ladwig's (2007) criticisms of this dimension, we maintain that a lack of empirical evidence relating to recognising difference in classrooms is insufficient justification for its removal from the framework. We are committed to determining the presence, or lack, of pedagogies described by the difference items. As with many others, we recognise the importance of valuing and working with difference as a good in and of 
itself and thus position its explicit inclusion as a separate dimension within the Productive Pedagogies framework as significant in working towards an integration of social justice within the pedagogical process (see for example, Delpit, 2006; Lingard \& Mills, 2007; Lingard 2007). We maintain that its presence as a separate dimension is imperative in light of concerns raised by the QSRLS around issues of social justice and difference, namely, that pedagogy, despite Queensland's diversity, was found to be socially inequitable, particularly disadvantaging Indigenous students and students from low socio-economic backgrounds. To these ends, we maintain that this dimension is central to realising a key intention of the model which is to promote high quality education especially for students from disadvantaged backgrounds (Lingard et al., 2001). However, in response to both the UWS critique of this dimension as poorly focused in its articulation of how difference might be valued and to Ladwig's critique (particularly given, along the lines of Ladwig's arguments about this dimension's lack of empirical evidence, that the pedagogies Group Identities and Active Citizenship were excluded from the NSW model of Quality Teaching), we recognise that there is a need to refine these items to sharpen their focus. We also recognise, in response to criticisms around cultural relevance that we can associate with the Narrative pedagogy, the need for further refinement of this item (see Nakata, 2001).

The UWS critiques of the difference dimension of Productive Pedagogies remind us of the importance of moving beyond a weaker politics of tolerance which this dimension has in some cases come to represent. We recognise that classrooms are cultural spaces where teacher and student identities come together to form particular relationships about which it is often difficult to generalise. We also acknowledge that place is important (McConaghy, 2006). In terms of specific communities and particular equity groups (e.g., poor rural communities), explicit (if infrequent) attention to difference in cultures, to future life chances and to citizenship roles may be crucial for improving such students' academic and social outcomes. However, such attention, as the UWS critique suggests, in its potential to reflect an uncritical or weak political frame in the valuing of different cultures or group identities, can endorse social inequities and perpetuate discriminatory relations of power and marginalisation. Our research investigating the requisite threshold knowledges necessary for teachers to critically engage learners in the problematising of such relations (see Martino, Lingard, \& Mills, 2004; Keddie \& Mills, 2007; Keddie, 2006) led us in our current study to focus more explicitly on the interrelationships between the observational data related to this dimension and the case study interview data. To these ends, there are specific questions around equity within the teacher and student interviews that seek to identify the participants' thoughts about marginalised or underachieving groups and how such issues of difference are being addressed within the classroom or broader school environment. Such information that generates insights into teachers' and students' views about issues of difference and group identity and in particular with what they see as the differences worthy or valuing/not valuing will supplement the classroom 
observations in relation to this dimension. It is also important to note here that the UWS concern with the productive pedagogies "uncritical" view of difference perhaps fails to consider the interrelatedness of the four dimensions. There is an explicit pedagogy in the dimension Intellectual Quality: knowledge as problematic that supports a critical view of knowledge. While, it is acknowledged that this pedagogy does not necessarily support a problematising of the dominant and oppressive knowledge constructions that are perpetuated by liberal tolerance discourses, it nonetheless can work with other pedagogies that promote the valuing of non-dominant cultural knowledges, to work in critical and socially just ways. In considering this dimension and our refinement of the study in response to such criticisms, we are also cognisant that the classroom may not be the most appropriate unit of analysis for observing a supportive environment for the production and positive valuing of difference and group identities.

\section{The Group Identities and Active Citizenship items}

Our response to the removal of the items Group Identities and Active Citizenship from the NSW model of Quality Teaching is similar to our defence of the inclusion of the difference dimension more broadly. We understand that a lack of empirical evidence for these pedagogies is insufficient for their omission and indeed see the promotion of positive group identities towards a sense of community and active citizenship instrumental in teaching for democracy. As Darling-Hammond (1997) notes: "If schools are to be agents of democracy, they must provide access to knowledge that enables creative thought and access to a social dialogue that enables democratic communication and participation" (p. 141). Our model of productive pedagogies understands schools and schooling along these lines - as sites of possibility for democracy and social justice (see Giroux, 2002). The explicit inclusion of group identity towards the promotion of active citizenship supports our positioning of teachers as oppositional intellectuals able to support students to think and act collectively against the grain of existing social arrangements towards a more equitable social world. The explicit inclusion of these items works as a metalanguage for teachers and schools to critically reflect on their practice to these ends. We are concerned here, for example, with how the fostering of positive group identities towards a sense of active and engaged citizenry in schools can support student agency. The explicit inclusion of these items examines the ways in which teachers support democratic processes to these ends such as providing genuine avenues for students to "have a say" in the classroom. We are also interested in how such processes play out beyond the classroom, for example, in terms of student input in the running of the school. To generate information about such processes we draw on the study's broader case material to supplement classroom observations of group identity and active citizenship. In particular, the teacher and student interview questions that explore thoughts on issues of equity and inclusion especially as these issues relate to the broader school climate as well as classroom and school decision making processes will provide important information along these lines. 
In relation to these items, we are also mindful of the potential uncertainty around their cross-curricula relevance and applicability. Certainly, our view is that they are applicable to all curriculum areas but that this may not be immediately apparent in the content of subjects such as mathematics. Mindful of issues of group identity, inclusivity, democratic process and active citizenship within the mathematics curriculum, Malloy (2002) identifies four distinguishing characteristics:

First, a problem solving curriculum should develop students' ability to draw on their mathematical knowledge to solve problems of personal and social relevance. Secondly, inclusivity and rights should be promoted by presenting mathematics from multiple perspectives that affirm the worth of individuals and groups from diverse backgrounds. Thirdly, there should be equal participation in decisions that affect students' lives, so that students use the classroom as a forum for public discussion of their own and others' ideas. Fourthly, students should experience equal encouragement for success through access to materials that develop critical habits of mind and engage them actively in learning mathematics. (in Goos, Stillman \& Vale, 2007, p. 106)

\section{The Narrative item}

In the original literature review for the Productive Pedagogies framework it is stated that "some non-mainstream learners, particularly Indigenous children, may learn best through narrative structures, because of strong oral traditions and narrative practices extant in their communities". Yet there is now a growing body of work that questions the assumptions made in this claim. First, significant research has been conducted into the structures and forms of Indigenous narratives, in Australia and elsewhere (for example, Sharifian, Rochecouste, Malcolm, Konigsberg, \& Collard, 2004; Olson \& Torrance, 2001; Honan, 2003) that draws our attention to the differences in the styles of storytelling and oral traditions within particular societies and the structures of the Western-English narrative styles. Secondly, there is a body of work by Indigenous researchers that critiques the emphasis on cultural "relevance" to the detriment of "a more focused approach to English-language teaching" (Nakata, 2001, p. 72; Thaman, 2003). Nakata in particular is critical of pedagogical approaches that impede Indigenous students' acquisition of the Western knowledge systems they require in order to effectively participate in contemporary Australian society. And thirdly, the existing observational scale item relating to narrative contributes to a binary view of its relation to expository modes of expression. Lemke's (1990) foundational work in this area, disrupts this binary, recommending that students need to understand that the expository mode and the "formal scientific style is not the whole of science". In particular Lemke recommends: 
Students should occasionally write fictional or fantasy narrative using scientific principles, construct scientific jokes or satires, read and write about historical events in science, write colloquial explanations of phenomena for younger students and parents, and so on. They also need to know when to stick to formal scientific style (on tests, in problem-solving and complex reasoning, in lab reports, etc.), and why. (Lemke, p. 174, emphasis added)

The complexity of the relationship between informal narrative styles and formal scientific language is further explored in Roth's (2005) more recent work that again emphasises that students need to become familiar with the appropriate use of both forms. The observational scale item for narrative has therefore been redeveloped for the current study to indicate the relationship between expository and narrative forms of language, and to take into account the need for pedagogies that explicitly provide students with exemplars and models of the particular purposes and contexts for using each form. To these ends, rather than simply measuring the extent to which narrative is present in the classroom, as represented in the earlier scale, the following descriptor for the highest score (5) in this item includes considerations of context and social/cultural appropriateness in the use of narrative:

Narrative is used in the explanation and illustration of the content and/or processes of the lesson, the forms used are particularly appropriate for the social and cultural groups of students present, and the content of the usage is appropriate for the particular curriculum area.

Refinement of this item allows us to acknowledge high quality pedagogies that appropriately blend informal narrative with discipline specific modes of expression. For example, in our current study we observed a Year 6 mathematics lesson adapted from a well known resource, "The Case of the Mystery Bone", in which students were presented with a series of simulated newspaper articles reporting on a murder mystery such that each successive article revealed new clues that had to be analysed. The lesson featured use of narrative that was appropriate to the group of students and helped to illustrate the mathematical content, which was concerned with collection of data on bone lengths and people's height and analysis of the relationship between these measurements.

\section{Student voice}

In contrast to the QSRLS, the present study includes students in the research. In particular the focus group interviews with students in case study schools seek to enrich the data produced through classroom observations. The student interviews explore issues of pedagogy (thoughts about how particular teaching/classroom practices, teachers and curriculum content might enable or constrain learning), assessment 
(thoughts about how particular assessment practices might support or hinder learning), equity (thoughts about issues of group marginalisation and discrimination of students within the school) and school environment (thoughts about how the broader school environment might be improved). Insights from students in these areas, absent from the QSRLS, will provide a broader and more comprehensive understanding of the four dimensions of productive pedagogy. The space created within this study for young people to theorise such issues is also highly significant its capacity to remedy some of the silencing of youth in educational discourses (see Martino \& Pallotta-Chiarolli, 2005).

\section{Including a Focus on Pedagogical Content Knowledge}

Observation alone cannot be used to determine the extent of a teacher's effect upon students' learning. It has been widely recognised, for instance, that teachers' pedagogical content knowledge (Schulman, 1986, 1987) has a significant impact upon their practice and there exists an extensive body of research in this area within mathematics and science education (e.g., Ball, 2000; Loughran, Mulhall, \& Berry, 2004; Ma, 1999). Hence, whilst the observation scales very closely reflect those used in the QSRLS, our classroom observations are accompanied by interviews with teachers enabling them to articulate the relationships between their knowledges of pedagogy and curriculum content (Baxter \& Lederman, 1999). These interviews will also be used to help refine the model for future phases of the research project.

\section{Conclusion}

In this paper we have provided a justification for the use of the Productive Pedagogies framework for undertaking a longitudinal study of classroom practices in Queensland government schools. However, in undertaking the QSTL we were aware of some of its limitations and critiques of the framework. Some of these concerns have been taken up in a slight reworking of the items, others have been incorporated into the questions that were asked as part of the interview process to accompany the observations. Early analysis of the data collected as part of this study indicate that the current set of QSTL observations will allow some useful comparisons to be made with the QSRLS completed in 2001, but at the same time will enable a greater understanding of what matters in classrooms for improving the academic and social outcomes of all students. Combined with the surveys and interviews with stakeholders a picture is also emerging of how the development of such classrooms can be supported by all levels of the education system. 


\section{Endnotes}

1 This dimension was originally referred to as Recognition of Difference, but in subsequent work has come to be referred to by the term used here (see Hayes et al., 2006).

2 These three dimensions are Intellectual quality, Quality learning environment and Significance.

\section{References}

Allen, J. (2003). Productive pedagogies and the challenge of inclusion. British Journal of Special Education, 30(4), 175-179.

Alton-Lee, A. (2004, April 19-20). Improving educational policy and practice through an iterative best evidence synthesis programme. Paper prepared for OECD-US Seminar, Evidence-based Policy Research, Washington D.C., US.

Ball, D. (2000). Bridging practices: Intertwining content and pedagogy in teaching and learning to teach. Journal of Teacher Education, 51(3), 241-247.

Baxter, J. A., \& Lederman, N. G. (1999). Assessment and measurement of pedagogical content knowledge. In J. A. Baxter \& N. G. Lederman (Eds.), Examining pedagogical content knowledge: The construct and its implications for science education (pp. 147161). Dordrecht, The Netherlands: Kluwer.

Boaler, J. (2002). Experiencing School mathematics: Traditional and reform approaches to teaching and their impact on student learning. Mahwah, NJ: Lawrence Erlbaum.

Boaler, J., Wiliam, D., \& Brown, M. (2000). Students' experiences of ability grouping - disaffection, polarisation and the construction of failure. British Educational Research Journal, 26(5), 631-648.

Bourdieu, P., \& Passeron, J-C. (1977). Reproduction in education, society and culture. London: Sage Publications.

Clark, A. (2008) History's children: History wars in the classroom. Coogee, NSW: University of New South Wales Press.

Comber, B., Badger, L., Barnett, J., Nixon, H., \& Pitt, J. (2001). Socio-economically disadvantaged students and the development of literacies in school: A longitudinal study (Vol. 1). Adelaide: University of South Australia.

Comber, B., \& Kamler, B. (2004). Getting out of deficit: Pedagogies of reconnection. Teaching Education, 15(3), 293-310.

Cooper, D. (2004). Challenging Diversity: Rethinking equality and the value of difference. Cambridge: Cambridge University Press.

Cope, B., \& Kalantsiz, M. (Eds.) (1995). The power of literacy. London: Falmer.

Darling-Hammond, L. (1997). The right to learn: A blueprint for creating schools that work. San Francisco: Jossey Bass.

Delpit, L. (2006) (new edition). Other people's children: Cultural conflict in the classroom. New York: The New Press. 
Donnelly, K. (2004). Why our schools are failing: What parents need to know about Australian education. Sydney: Kingston, Duffy and Snelgrove.

Dusseldorp Skills Forum. (2005). How young people are faring: Key indicators 2005. An update about the learning and work situation of young Australians. Glebe, NSW: Dusseldorp Skills Forum.

Frankenstein, M. (1997). In addition to the mathematics: Including equity issues in the curriculum. In J. Trentacosta \& M. J. Kenny (Eds.), Multicultural and gender equity in the mathematics classroom: The gift of diversity (pp. 10-22). Reston, VA: National Council of Teachers of Mathematics.

Frankenstein, M. (2001, January 15-19). Reading the world with math: Goals for a critical mathematical literacy curriculum. In B. Lee (Ed.), Mathematics shaping Australia (pp. 53-64). Proceedings of the $18^{\text {th }}$ biennial conference, Australian Association of Mathematics Teachers. Adelaide: Australian Association of Mathematics Teachers.

Giroux, H. (2002). Democracy, freedom and justice after September 11: Rethinking the role of educators and the politics of schooling. Teachers College Record, 104(6), 1138-1162.

Goos, M., Stillman, G., \& Vale, C. (2007). Teaching secondary school mathematics: Research and practice for the $21^{\text {st }}$ century. Sydney: Allen \& Unwin.

Gutstein, E. (2003). Teaching and learning mathematics for social justice in an urban, Latino school. Journal for Research in Mathematics Education, 26, 115-141.

Harding, A., McNamara, J., Tanton, R., Daly, A., \& Yap, M. (2006, August 20-26). Poverty and disadvantage among Australian children: A spatial perspective. Paper presented at the $29^{\text {th }}$ General Conference of the International Association for Research in Income and Wealth, Joensuu, Finland.

Hargreaves, A. (2003). Teaching in the knowledge society: Education in the age of insecurity. Maidenhead: Open University Press.

Hayes, D., Johnston, K., \& King, A. (2006, November 27-30). The disruptive possibilities of looking in classrooms. Paper presented at the Australian Association of Research in Education Conference, Adelaide.

Hayes, D., Mills, M., Christie, P., \& Lingard, B. (2006). Teachers and schooling making a difference: Productive pedagogies, assessment and performance. Crows Nest, NSW: Allen \& Unwin.

Honan, E, (2003). Schooled literacies? The use of vernacular literacy practices in Papua New Guinean communities. Prospect, 18(3), 36-52.

Ireson, J., Hallam, S., \& Plewis, I. (2001). Ability grouping in secondary schools: effects on pupils' self-concepts. British Journal of Educational Psychology, 71(2), 315-26.

Keddie, A. (2006). Pedagogies and critical reflection: Key understandings for transformative gender justice. Gender and Education, 18(1), 99-114. 
Keddie, A., \& Churchill, R. (2004). Power, control and authority: Issues at the centre of boys' relationships with their teachers. Queensland Journal of Teacher Education, 19(1), 13-27.

Keddie, A., \& Mills, M. (2007). Teaching boys: Classroom practices that work. Crows Nest: Allen \& Unwin.

Ladwig, J. (2005). Monitoring the quality of pedagogy. Leading E Managing, 11(2), 70-83.

Ladwig, J. (2007). Modelling pedagogy in Australian school reform. Pedagogies: An International Journal, 2(2), 57-76.

Lemke, J. (1990). Talking science: Language, learning and values. Norwood, NJ: Ablex.

Lingard, B. (2007). Pedagogies of indifference. International Journal of Inclusive Education, 11(3), 245-266.

Lingard, B., Hayes, D., \&. Mills, M. (2003). Teachers and productive pedagogies: Contextualising, conceptualising, utilising. Pedagogy, Culture and Society, 11(3), 397-422.

Lingard, B., Hayes, D., Mills, M., \& Christie, P. (2003) Leading Learning. Maidenhead: Open University Press.

Lingard, B., Ladwig, J., Mills, M., Bahr, M., Chant, D., Warry, M., et al. (2001). The Queensland School Reform Longitudinal Study. Brisbane: Education Queensland.

Lingard, B., Martino, W., Mills, M., \& Bahr, M. (2002). Addressing the Educational needs of Boys. Canberra: Department of Education Science and Training (DEST).

Lingard, B., \& Mills. M. (2007). Pedagogies making a difference: Issues of social justice and inclusion. International Journal of Inclusive Education, 11(3), 233-244.

Louden, W., Rohl, M., Barratt-Pugh, C., Brown, C., Cairney, T., Elderfield, et al. (2005). In teachers' hands: Effective literacy teaching practices in the Early Years of schooling. Australian Journal of Language and Literacy, 28(3). [Special Edition.]

Loughran, J., Mulhall, P. \& Berry, A. (2004). In search of pedagogical content knowledge in science: Developing ways of articulating and documenting professional practice. Journal of Research in Science Teaching, 41(4), 370-391.

Luke, A., Freebody, P., Shun, L., \& Gopinathan, S. (2005). Towards research-based innovation and reform: Singapore schooling in transition. National Institute of Education, Singapore. Asia Pacific Journal of Education, 25(1), 5-28.

Luke, A., \& Hogan, D. (2006). Redesigning what counts as evidence in educational policy: The Singapore model. In J. Ozga, T. Seddon, \& T. Popkewitz, (Eds.), World yearbook of education. Educational research and policy: Steering the knowledgebased economy (pp.173-174). London: Routledge.

McConaghy, C. (2006). Schooling out of place. Discourse: Studies in the Cultural Politics of Education, 27(3), 325-339.

McGaw, B. (2006, May 16). Education and social cohesion. Dean's Lecture Series, Melbourne Education Research Institute, Melbourne, Australia. 
Ma, L. (1999). Knowing and teaching elementary mathematics: Teachers' understanding of fundamental mathematics in China and the United States. Mahwah, NJ: Lawrence Erlbaum Associates.

Malloy, C. (2002). Democratic access to mathematics through democratic education: An introduction. In L. D. English (Ed.), Handbook of international research in mathematics education (pp. 17-25). Mahwah, NJ: Lawrence Erlbaum Associates.

Marsh, J. (2007). New literacies and old pedagogies: Recontextualizing rules and practices. International Journal of Inclusive Education, 11(3), 267-281.

Martino, W., \& Berrill, D. (2003). Boys, schooling and masculinities: Interrogating the "right" way to educate boys. Education Review, 55(2), 99-117.

Martino, W., Lingard, B., \& Mills, M. (2004). Addressing the educational needs of boys: A question of teacher threshold knowledges? Gender and Education, 16(4), 435-454.

Martino, W., \& Pallotta-Chiarolli, M. (2003). So what's a boy? Addressing issues of masculinity and schooling. Maidenhead: Open University Press.

Mills, C., \& Gale, T. (2007). Researching social inequalities in education: Towards a Bourdieuian methodology. International Journal of Qualitative Studies in Education, 20(4), 433-447.

Mills, M. (1996). Homophobia kills: Disruptive moments in the educational politics of legitimation. British Journal of Sociology of Education, 17(3), 315-326.

Mills, M. (1997). Towards a disruptive pedagogy: Creating spaces for student and teacher resistance to social injustice. International Studies in Sociology of Education, 7(1), 35-55.

Munns, G. (2007). A sense of wonder: Pedagogies to engage students who live in poverty. International Journal of Inclusive Education, 11(3), 301-315.

Nakata, M., (2001). The place of English in Indigenous communities. In P. Freebody, S. Muspratt, \& B. Dwyer (Eds.), Difference, silence and textual practice: Studies in critical literacy. Cresskill, NJ: Hampton Press.

Newmann \& Associates (1996). Authentic achievement: Restructuring schools for intellectual quality. San Francisco: Jossey-Bass.

NSW Department of Education \& Training. (2007). Quality Teaching in Curriculum K-12. Retrieved May 31, 2007 from http://www.curriculumsupport.education.nsw. gov.au/qualityteach/index.htm

Olson D., \& Torrance, N. (Eds.) (2001). The making of literate societies. Massachusetts: Blackwell.

Pendergast, D., Flanagan, R., Land, R., Bahr, M., Mitchell, J., Weir, K., et al. (2005). Developing lifelong learners in the middle years of schooling. Brisbane: The University of Queensland.

Perry, T., Steele, C., \& Hilliard, III. (2003). Young, gifted and black: Promoting high achievement among African-American students. Massachusetts: Beacon Press.

Routti, J., \& Ylä-Anttila, P. (2006). Finland as a knowledge economy: Elements of success and lessons learned. Washington, DC: World Bank. 
Roth, W. M. (2005). Talking science: Language and learning in science classrooms. Lanham, Maryland: Rowman \& Littlefield.

Sahlberg, P. (2007). Education policies for raising student learning: The Finnish approach. Journal of Education Policy, 22(2), 147-171.

Sarra, C. (2006). Young and black and deadly: Strategies for improving outcomes for indigenous students. In M. Keeffe \& S. Carrington (Eds.), Schools and diversity (pp. 63-79). Frenchs Forest, NSW: Pearson.

Schulman, L. (1986). Those who understand: Knowledge growth in teaching. Educational Researcher, 15, 4-14.

Schulman, L. (1987). Knowledge and teaching: Foundations of the new reform. Harvard Educational Review, 57, 1-22.

Sellar, S., \& Cormack, P. (2006, November 29). (Re)conceptualising Middle Years pedagogy. Paper presented as part of the Symposium Pedagogical Reform in the Middle Years, Australian Association for Research in Education Conference, Adelaide. Retrieved May 31, 2007, from http://www.aare.edu.au/06pap/cor06437.pdf

Sharifian, F., Rochecouste, J., Malcolm, I. G., Konigsberg, P., \& Collard, G. (2004). Improving understanding of Aboriginal literacy: Factors in text comprehension. A project of the $\mathrm{ABC}$ of Two-Way Literacy and Learning. WA: Department of Education and Training, WA.

Shegar, C., \& Abdul Rahim, R. (2005). Tamil Language Instruction in Singapore: A preliminary report on findings of classroom pedagogical practice. Singapore: Centre for Research in Pedagogy and Practice, National Institute of Education, Nanyang Technological University, Singapore.

Singh, P., \& Taylor, S. (2007). The new equity deal for schools: A case study of policymaking in Queensland, Australia. British Journal of Sociology of Education, 28(3), 301-315.

Simola, H. (2005). The Finnish miracle of PISA: Historical and sociological remarks on teaching and teacher education. Comparative Education, 41(4), 455-470.

Sizer, T. (1996). Horace's Hope. Boston: Houghton Mifflin.

Skovmose, O., \& Valero, P. (2002). Democratic access to powerful mathematics in a democratic country. In L. English (Ed.), Handbook of international research in mathematics education (pp. 383-408). Mahwah, NJ: Lawrence Erlbaum Assoc.

Snyder, I., (2008). The literacy wars: Why teaching children to read and write is a battleground in Australia. Sydney: Allen \& Unwin.

Teese, R., \& Polesel, J. (2003). Undemocratic schooling: Equity and quality in mass secondary schooling. Melbourne: Melbourne University Press.

Thaman, K. H. (2003). Decolonizing Pacific studies: Indigenous perspectives, knowledge and wisdom in higher education. The Contemporary Pacific, 15(11), 1-18.

Thomson, P. (2002). Schooling the rustbelt kids: Making the difference in changing times. Crows Nest: Allen \& Unwin. 
Thomson, S., Cresswell, J., \& De Bortoli, L. (2004). Facing the future: A focus on mathematical literacy among Australian 15-year-old students in PISA 2003. Camberwell, Australia: ACER.

Wiliam, D., \& Bartholomew, H. (2004). It's not which school but which set you're in that matters: The influence of ability grouping practices on student progress in mathematics. British Educational Research Journal, 30(2), 79-93. 
Copyright of Australian Educational Researcher is the property of Australian Association for Research in Education and its content may not be copied or emailed to multiple sites or posted to a listserv without the copyright holder's express written permission. However, users may print, download, or email articles for individual use. 